\title{
STUDY OF FOREMAN-LEVEL TASK AUTOMATION IN THE US CONSTRUCTION INDUSTRY
}

\author{
Carl T. Haas (haas@mail.utexas.edu) \\ Associate Professor, University of Texas at Austin, Austin, TX, 78712, USA. \\ Christine Alemany (calemany@proxicom.com) \\ Consultant, Proxicom, 55 Broad Street, New York, NY, 11222, USA. \\ Hyoungkwan Kim (hyoungkwan@mail.utexas.edu) \\ Graduate Research Assistant, University of Texas at Austin, TX, 78712, USA
}

\begin{abstract}
Three aspects of the effects of computers on the work of construction foremen were investigated: time saved, foremen's reactions to and experiences with task automation, and trends in foreman-level task automation. Over 179 foremen employed by six companies utilizing foreman-level task automation were surveyed as part of this research effort. Of the 179 foremen who responded, fifty-four percent use a computer at work. Based on the responses, the average amount of time saved per day due to computer use was 14 minutes. In addition, a computer-using foreman spends $10 \%$ more time supervising than his noncomputer using counterpart. This may be assumed to represent a significant increase in potential production by the foreman and his crew.
\end{abstract}

Keywords: automation, computer, construction, foreman, productivity.

\section{INTRODUCTION}

Since foremen influence approximately $33 \%$ of a construction project's budget, the effectiveness of foremen greatly affects project success [1]. Foremen supervise crews ranging in size from 8 to 12 people. As first-line supervisors, foremen are expected to perform several tasks during a construction project: interpreting plans and drawings; assigning crew members to construction tasks; providing discipline, training, and guidance to crew members; materials, equipment, and tool procurement; short interval scheduling; and completing paperwork. Paperwork includes items such as daily diaries, reports and time records.

Modern project management has increased the amount of paperwork that foremen are required to complete in order to obtain the necessary information for automated project controls and payroll. Foremen see this paperwork as burdensome, though it is essential for management [4]. Foremen could spend more time planning, working, and supervising their crews by decreasing the time spent on paperwork and other non-construction related tasks, thus improving productivity. Automating these tasks with computer use is one way to achieve this goal.

Computer use at the foreman level, or foremanlevel task automation, greatly varies across the construction industry. Although most construction foremen do not use computers in the workplace, several leading firms in the construction industry have begun to train their first-line supervisors to use computers on the job site, both in and out of the field.

\subsection{Research background.}

The proliferation of computers for information generation and processing on a project site traditionally has been limited to the office staff (superintendent, project manager, project engineers, office engineers, and field engineers) and architectural/engineering designers. Designers and construction managers may exchange information electronically. However, this information is manually communicated to field personnel. In general, fieldlevel project information is manually collected on a daily, weekly, biweekly, and monthly basis. The field information is then transmitted to data entry for construction management's use.

Construction managers analyze field-level information in order to make decisions. Both the source and output of construction management endeavors must be converted from an automated format to a manual format for field use, which opens the possibility of transcription errors. This traditional 
method of information transfer in a construction project is illustrated in Figure 1.

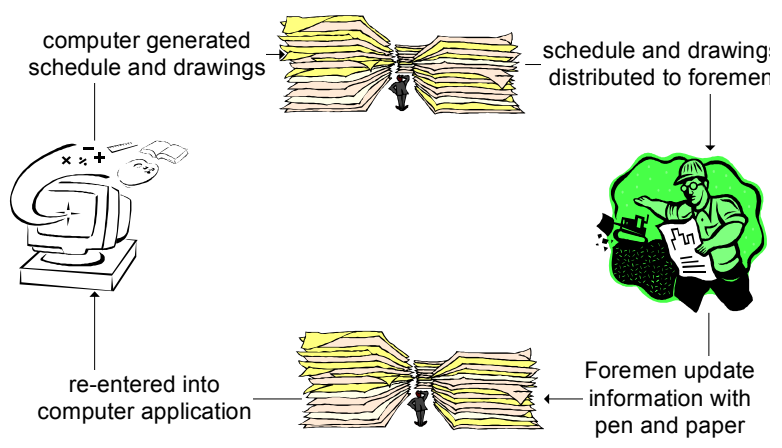

Figure 1. Manual information transfer at the field level [4]

In the above figure, electronically stored information is transferred into a manual format for field dissemination. Errors in this transmission may occur, supplying the field with inaccurate information. Returning this information to management and recoding it into an electronic format is also susceptible to the same error, compounding problems of accuracy and reliability. Computers on the foreman level can help remedy these problems while improving documentation without adding to the foreman's workload.

\subsection{Research methodology}

The research effort began in 1998 with a literature search of related topics. Telephone and personal interviews with off-site construction management were performed. The purpose of the interviews was to receive qualitative responses that would provide rich, in-depth information on current practices for the implementation of computers on the foremen level. The interviews were performed over a length of seven weeks in the summer of 1999. After completing 12 interviews, a survey was formulated using the responses received during the interviews to assist with the construction of the survey questions.

To ensure its quality and reliability, the survey was beta tested. It was edited by academic experts in construction, human resources, and statistical analysis. Necessary adjustments were made to the survey after each beta test. After the last beta test, companies with foreman-level task automation in use were located. Out of the 59 companies and 17 union contacts that were contacted, six companies were found with foreman-level task automation. All six companies agreed to participate in the study. These companies ranged from union to non-union, mediumsized to large, and consisted of general, mechanical, and electrical contractors.

The final version of the survey was distributed by mail during the fall of 1999. The companies participating in the study distributed the survey during foremen meetings. The acquired survey data was analyzed and interpreted. This paper summarizes the conclusions of the research.

\section{CURRENT PRACTICES OF FOREMAN-LEVEL TASK AUTOMATION}

Several companies require their foremen to use a computer in the hope of decreasing the amount of time that foremen and office personnel spend completing paperwork. However, each company has a different approach to saving their foreman's time. Companies chose to automate different tasks at the foreman-level and allowed foremen differing degrees of autonomy. The differences in the degree of autonomy associated foreman-level task automation can be traced to the expectated computer skills of a foreman. It is important to determine if foremen are capable of operating a computer with full autonomy or if autonomy should be restricted to ease foremen resistance to task automation.

\subsection{Interpreting plans and drawings}

Foremen spend a considerable amount of time interpreting drawings in the field. Unfortunately, field sketches, change orders, and requests for information are physically attached to a drawing as the project progresses, leaving the foreman to integrate all the information in those drawings. A foreman may need to interpret ambiguous information or draw an additional field sketch integrating all of the information into one drawing. This takes considerable time. By using 3-D modeling, a company can decrease the number of ambiguities while integrating all of the information from various disciplines: structural, mechanical, electrical, and architectural. This new capability decreases the amount of time that a foreman spends interpreting drawings [3].

\subsection{Locating updated drawings}

Project designs are continuously being updated as the project progresses. In a typical project, the updated design is located in the site office and is not usually updated each day. Often foremen have to track down changes by following office paper trails. By using CAD drawings to integrate information and to give foremen immediate access in the field, a company can considerably decrease the amount of time that a foreman spends trying to locate updated drawings.

\subsection{Material, tool, and equipment procurement}

Today, a company can create databases tracking the location of materials, tools, and equipment. In 
today's construction environment, progressive companies use computers for inventory control. With bar coding and a GPS system, a company can automate this task one step further and achieve a new capability. Using bar scan for inventory control while a GPS system tracks the location of these items and the location of the foreman requesting the items, the warehouse can deliver materials, tools and equipment to the foreman. This can enable a foreman to order materials, tools, and equipment from the field, without leaving his crew. Even without GPS, bar coding decreases the amount of time needed to input the information describing the item and the foreman requesting the item, which also decreases the amount of time that a foreman spends away from his crew. Bar coding also reduces transcription errors and their associated repercussions.

\subsection{Time reporting}

Some companies have automated time keeping reporting by providing foremen with a program that requires as much computer skills as required for operating an ATM machine. In this case, it is assumed that a foreman is not capable of operating a computer with complete autonomy and is trained to use in-house software. This keyless entry program prompts the foreman to pick one of three choices at each interval. Instead of typing information into the computer, the foreman is provided with barcodes and a scanner to input a crew member's name, hours worked, and activity that he or she worked on. Automated time keeping not only saves the foreman time but also creates a direct line of communication between a foreman and the accounting dpartment.

\subsection{Short interval scheduling}

Foremen can be trained to use commercially available software to conduct short interval scheduling. As with the case with automated time keeping, using computers for short interval scheduling saves both the foreman and the office staff time because he is no longer forced to duplicate previously scheduled activities. The office only needs to import the foreman's schedule into the project's CPM schedule, saving the office staff sizable amounts of time.

\section{SURVEY ANALYSIS}

All six of the companies who agreed to participate returned the survey to the researcher. One hundred seventy-nine surveys were received from the participating companies. The data was analyzed using Microsoft (MS) Access, MS Excel and SPSS. Means, standard deviations, and various relationships were determined from the data.
According to research in information technology, a user's age, tenure, education, and self-efficacy affect his attitude toward an information system. These effects were expected in the foremen's responses to survey questions on foreman-level task automation. However, this was not the case. Despite relationships between age, number of years in a supervisory position, self-efficacy, education, and perceived usefulness of an information system found in previous research, a significant relationship could not be found in this study.

\subsection{Age and tenure}

Because of their effects on worker attitude, age and the duration of service in a supervisor role previous to task automation may influence a user's attitudes towards new technology. It is important to determine the respondents' demographics because it is one key to understanding the respondents' answers to survey questions.

The average age of the entire sample is 42.6 years old (standard deviation 8.3). The 42.6 years old average age is slightly higher than average age of construction workers found from the 1997 Center to Protect Workers' Rights Chart Book. The higher average age was expected because of the experience that is required to be promoted to a foreman.

The respondents' experience in construction varied from two months to forty-five years. On average, the respondents have spent 20.7 years (standard deviation 8.3) in the construction industry. The respondents experience as a construction foreman also greatly varied, from seven days to thirty years. The respondents averaged 9.4 years (standard deviation 7.1) as construction foremen. The wide range in ages was desired in order to avoid responses biased by age or fear of new technology.

\subsection{Workforce education}

The survey asked for a numeric response for number of years of education received. The average of the amount of formal education was 12.3 years (standard deviation 1.6). Figure 2 shows the percentage of the foremen that obtained educational degrees of some sort. The majority of the respondents obtained a high school degree. Other degrees obtained were GED (General Educational Development), associate, and vocational. These statistics show that many foremen have at minimum a high school diploma or GED equivalent education However, the number of workers who did not or could not fill out the survey from illiteracy is not known.

\subsection{Foremen computer use at work}


Of the 179 foremen who responded, fifty-seven percent use a computer at work. Of those foremen, ninety-two percent used computers in the job site office while fourteen percent used them in the field. Of the foremen who used computers, forty-eight percent believed that they spent more time in direct supervision of their crews since using a computer at work. Only twenty-nine percent of the foremen using computers at work responded that they performed less rework as a result of using a computer on the job. Although foremen were generally not supportive about the effectiveness of foreman-level task automation, seventy-seven percent of the foremen who used computers at work believed that their company saved money by having them use computers.

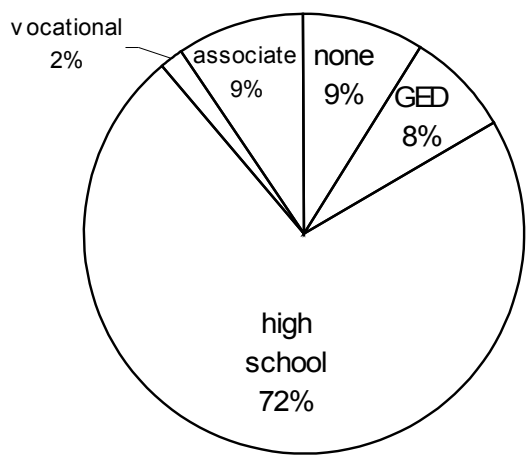

Figure 2. Percentage of respondents with various degrees

Foremen were also asked to estimate the average length of a work day and the time devoted to performing various tasks on an average day. Foremen could also add tasks that were not included in the list above (Table 1). All of the differences between the time spent with computer use and without computer use were statistically significant. The results show that foremen who use computers at work spend less time at work while spending more time supervising. Additionally, the average workday was decreased by 14 minutes after forman-level task automation was introduced. If one assumes that a job has 15 foreman working eight hours each day at $\$ 12$ an hour, and each foreman works fifty-two, five day weeks out of the year, that job can save $\$ 10,764$ each year. This savings is solely due to the time savings of fourteen minutes and does not include productivity increases due to increased supervision.

Table 1. Comparison of the number of hours devoted to tasks between without and with a computer

\begin{tabular}{|l|r|r|}
\hline \multicolumn{1}{|c|}{ Tasks } & Without & \multicolumn{1}{c|}{ With } \\
\hline Length of workday & 9.03 & 8.80 \\
\hline Interpreting drawings & 1.32 & 1.01 \\
\hline
\end{tabular}

\begin{tabular}{|l|r|r|}
\hline \multicolumn{1}{|c|}{ Tasks } & \multicolumn{1}{c|}{ Without } & \multicolumn{1}{c|}{ With } \\
\hline Locating plans & 0.73 & 0.55 \\
\hline Material procurement & 0.91 & 0.78 \\
\hline Tool procurement & 0.53 & 0.43 \\
\hline Equipment procurement & 0.63 & 0.52 \\
\hline Equipment procurement & 0.93 & 0.74 \\
\hline Scheduling & 3.00 & 3.81 \\
\hline Time reporting & 0.79 & 0.68 \\
\hline Other & 0.19 & 0.28 \\
\hline
\end{tabular}

The amount of time spent on individual tasks before and after the introduction of foreman-level task automation was compared by using the percentage of time spent on each task to the average workday length. By looking at Figure 3, one can also see that a foreman using task automation would spend, on average, ten percent more time directly supervising his crew than non-computer using counterpart. He also spends less time completing non-supervisory tasks than his non-computer using counterpart.

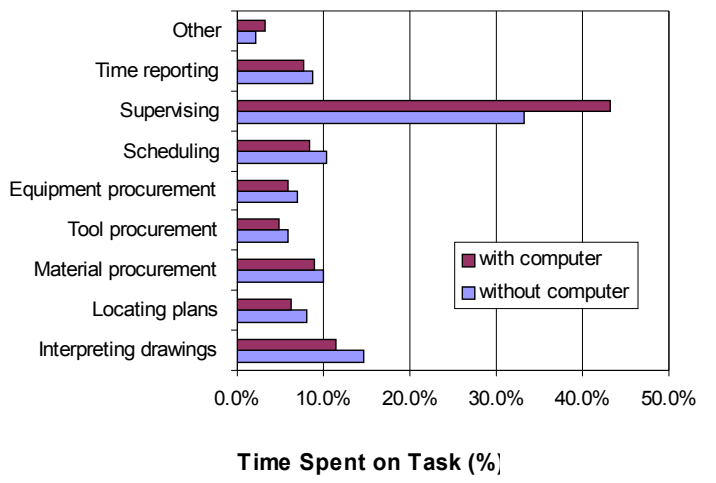

Figure 3. Percentage of time spent on each task

\subsection{Trends in the use of foreman-level task automation}

Foremen who presently use computers at work were asked which of their everyday tasks were automated by a computer five years ago, three years ago, and in the present. The time intervals were chosen because of the present lack of foreman-level task automation in the construction industry. Respondents could choose from several of the foreman-level automated tasks identified during the literature search and expert interviews and could add additional tasks if necessary. From their responses, trends in automation implementation can be seen. The use of foreman-level task automation has increased in the seven companies currently using foreman-level task automation (Figure 4). In Figure 4 , automation level represents the summation of the number of foremen who used a computer. 


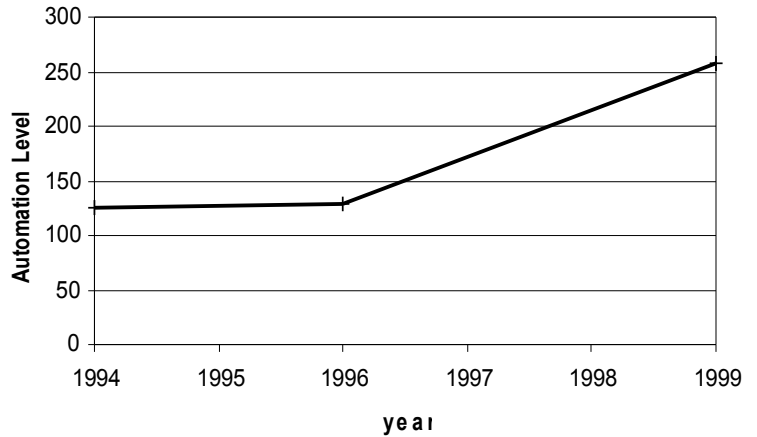

Figure 4. Foreman-level task automation trend

Once trend charts were created, three classes of foreman-level task automation could be deciphered based on the trends in the level of use. The first class, or Class 1, consists of five tasks: time reporting, accessing other information, communicating with others on a project, accessing the latest drawing revisions, and visualizing future and present work through 3-D drawings. Class 1 Automation is rapidly increasing in implementation within the companies surveyed.

The next class, or Class 2 Automation, is slowly increasing in use and has a lower usage than Class 1 Automation. This class consists of six tasks: ordering tools, locating tools, locating scaffolding, recording job progress, locating materials, and ordering materials.

The last class of foreman-level task automation, named Class 3 Automation, consists of three tasks: ordering equipment, ordering scaffolds, and locating equipment. Use of Class 3 Automation is either stable or decreasing. The reasons for decrease in use are not known.

\subsection{Foreman requests for foreman-level task automation.}

Respondents were asked which of the foremanlevel automated tasks they wanted implemented in the future. The list of tasks presented to them was compiled from the literature search and the expert interviews.

Companies should concentrate on tasks having greater affirmations for future automation. Such tasks are time reporting, locating updated drawings and plans, and ordering materials. Time reporting and locating updated drawings and plans are classified as Class 1 Automation while ordering materials is Class 2 Automation. Industry should take note of foremen requests and trends in use when deciding on future implementation of foreman-level task automation.
Among the 179 foremen who responded, fiftyseven percent use a computer at work. Based on the responses, the average amount of time saved per day due to computer use was about 14 minutes. This represents a small direct labor savings. However, a computer-using foreman spent ten percent more time supervising than his counterpart who does not use computers. This may represent a significant increase in the productivity of a foreman and his crew.

Construction companies should consider automation trends and foremen opinions when planning future foreman-level task automation. Those tasks having greater requests from foremen for future automation are time reporting, locating updated drawings and plans, and ordering materials.

\section{REFERENCES}

[1] J. D. Borcherding. University of Texas, Personal Interview. May 2,1999.

[2] The Center to Protect Workers' Rights. The Construction Chart Book. The Center to Protect Workers' Rights Publications: Washington, D.C.. 1998.

[3] S. Holy, B. Song, Ben; and R, Wubbenhorst. Implementation of an Integrated 3-D Information System for EPC Projects. Fluor Daniel. 1999.

[4] R. Wubbenhorst, Pen Computer Applications and Potential for Collecting and Transferring Field Level Construction Information. Masters Thesis, Department of Building Construction, The University of Florida. May 1996.

[5] R. Wubbenhorst, Fluor Daniel, Personal Interview. April 21,1999.

\section{CONCLUSION}

